\title{
Trends and dynamics in material and energy flows analysis in an urban context. A case study of a city with an emerging economy
}

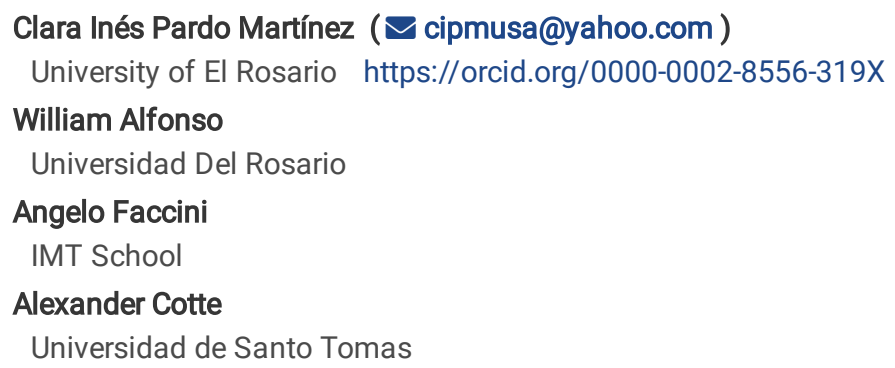

Version of Record: A version of this preprint was published at Energy, Sustainability and Society on July 12th, 2021. See the published version at https://doi.org/10.1186/s13705-021-00300-w. 


\section{Abstract}

Background: Currently, most of the world's population lives in cities, and this trend of the rapid urbanization of the population affects the increase in the demand for products, goods and services. To effectively design policies for urban sustainability it is important to know the trends of the flows of energy and materials that enter and leave the city. This knowledge is essential to recognize key elements characterizing the future urban growth and to be able to face supply challenges in the future. This paper presents the analysis of the flows of energy and materials (urban metabolism) in the city of Bogotá, covering a time span from 2001 to 2017. Urban flows are also characterized in terms of their temporal evolution with respect to the population growth, in order to compare and identify the changes in the main input flows, wealth production, emissions and waste in the city.

Results: The results of the analysis are also compared with other selected large urban agglomerations in Latin America and worldwide, highlighting similarities and inferences. The results show that in Bogotá, there was a decrease in some of the material flow in recent years, such as the consumption of water and the generation of discharge, while there was an increase in the consumption of energy and cement and the production of $\mathrm{CO}_{2}$ emissions and construction materials. Solid waste production remained relatively stable. With respect to the other large cities considered, we observe that the 10-year growth rates of the metabolic flows with respect to the population growth are lower, in particular when compared with the other urban agglomeration of Latin America.

Conclusions: The findings of this study are important to advance the characterization of the trends in material and energy flow in the city and contribute to the consolidation of a baseline that allows for the definition and evaluation of the different impacts of public policy that promotes the sustainability of the city in the coming decades.

\section{Introduction}

More people live in cities, and statistics show that, in the next 30 years, it is expected that more than $60 \%$ of people will live in cities (United Nations, 2019); therefore, it is essential to achieve sustainability and to provide policy and decision makers with instruments allowing for the reduction of the effects and impacts of current and future urbanization on the environment. In this context, it is important to know and analyse how the flows of energy and material feeding the city operate and are transformed in order to formulate and implement instruments that guarantee the quality of life and a healthy environment.

According to the United Nations Development Program (UNDP) (2012), globally, cities occupy 3\% of the earth's surface, produce $80 \%$ of the gross domestic product, consume $75 \%$ of natural resources, and produce $50 \%$ of the solid waste and between $60 \%$ and $80 \%$ of greenhouse emissions. These figures have reached a critical point, and cities have become a fundamental pivot for reducing GHG emissions and reduce the increase of the global temperature. However, as stated by the COP 21 and the following Paris agreement, cities have a potential to improve their efficiency; for example, it is estimated that although global water consumption can be reduced by $30 \%$ and energy by $30-50 \%$, infrastructure investments years of approximately 41 trillion dollars would be required for the next 20 (UN, 2015). Moreover, the main important megacities of the world are responsible for on average $9 \%$ of global electricity consumption and $13 \%$ of the solid waste production, account for $7 \%$ of the global population and generate an important share of the gross domestic product (Kennedy et al., 2015); therefore, it is important to analyse different flows and production of goods, services and pollution to meet the requirements of the population and decrease the environmental problems and impacts.

Policies for sustainability and management of urban areas require understanding the demands of natural resources flows and the environmental impacts that are generated. The material flow analysis (MFA) allows us to demonstrate how a relationship of inputs and outputs that can promote eco-efficiency is generated, which is essential for policy makers and decision makers to formulate an urban policy that guarantees sustainability and productivity improvements and competitiveness (Moore et al., 2013).

In recent years, the analysis of urban flows, the "urban metabolism" is emerging as a reliable tool to analyse and design urban sustainability policy (Kennedy, 2007). Indeed, several studies have shown that at the urban level, knowing, analysing and evaluating the flow of materials that comprise the consumption of resources and energy are fundamental to determine the environmental effects and impacts of consumption and its transformations, possibilities of urban resilience and actions and/or options that allow for the achievement of urban sustainability over time in a differentiated way (Rosado, et al., 2017, Ferrão and Fernandez, 2013, Grimm and Wissel, 1997).

Urban flows can be analysed by means of two approaches (Barles, 2010). First, there is research and decision support that evaluates the following factors:

1. Urban biogeochemistry processes, such as studies of Pataki et al. (2011) and Lin (2014) that demonstrated an integral solution and opportunities to integrate biogeochemical science in the design and evaluation of urban infrastructure and to generate synergies between environmental quality and food security through innovation and new technologies to reduce waste and pollution;

2. Effects of the material and energy demands in the cities that suggest that the present pattern of energy and resources lead to a reduction in and scarcity of natural resources, degrading ecosystems and affecting the quality of life in urban areas, where the objective is to promote 
energy and resource efficiency, to improve urban systems, and to increase and sustain economic growth (EEA, 2015, Song et al., 2016);

3. Biogeochemical and social operation interactions that analyse how natural cycles and society could disturb the urban ecosystem, understanding that the urban ecosystem and circular economy, among others, are important to formulate governance and policies that promote sustainable development in cities. Various studies have analysed these elements, such as Prendeville et al. (2018), who analysed these issues in six cities, and Czamanski and Broitman (2018), who suggest the importance of incorporating new innovation and structures that generate interurban migration patterns to achieve sustainable development.

The second approach is a tool to promote sustainable development challenges and requests to achieve the following goals:

1. Decoupling (to decrease the dependence between growth and use of natural resources), where studies have demonstrated that a decoupling effect seems to have occurred in G20 countries with a strategies for emissions, energy consumption, and economy decoupling supported by diversification, sustainable energy consumption mix and stable economic growth maintenance, and circular economy seeks to decouple global economic development from finite resource consumption (Pao and Chen, 2019, Giampietro, 2019);

2. Dematerialisation (consumption of fewer materials), which implies that the decrease in the intensity of material utilization depends on the increase in material circulation and social overall level of cleaner production and more effective use of the existing inputs and raw materials (Dai and Liu, 2018, Kemp-Benedict, 2018);

3. Decarbonisation (consumption of less carbon), which implies that urban low transitions, through re-ordering of urban infrastructure and new technologies, have achieved a high decarbonisation of the electricity sector, of new energy business models at the distribution level and of new power distribution architectures (Tozer, 2019, Silvestre et al., 2018);

4. Closing of material loops, where Tomić and Schneider (2018) and Patricio et al. (2015) demonstrated that energy recovery of waste might suggest to "close the loop" in the whole waste recovery mind-set, and strategies such as industrial symbiosis, resource recovery or re-use can be good approaches to achieve materials loop closure and decrease dependence on external sources. These studies are important because they allow one to design indicators, to determine sustainability targets and to establish new strategies to achieve resource efficiency policies and programmes.

The present study consists in a material flow analysis of Bogotá from household perspective, a city located in an emerging economy. Bogotá is selected because it is the capital of Colombia, a country with an emerging economy that contributes to a quarter of the country's internal product with a high level of industrialization, the presence of different productive activities and a city with the highest population concentration that currently faces many environmental challenges. This type of study can be an input to develop more effective programmes for sustainable development in Colombian urban areas.

The research questions that guide this paper are: i. What are the trends of material and energy flows in the city selected and how do they change over time?; and ii. What is the performance of material and energy flows in comparison with other Latin American Countries?. To resolve these questions, this study applies different flows analysis based on inputs and outputs, relationship with gross domestic product and comparison of performance of other cities through normalized data.

Here trends and dynamics over time are analysed with the aim to determine the temporal evolution of input and output flows over 10 and 17 years, with a focus on 2017. Data are also compared with the 10 years temporal evolution of a selected number of Latin America large urban agglomerations. Results show that Bogotá has generated sustainable processes by increasing its GDP while maintaining an environmental pressure lower with respect to the other cities as input to design adequate policies according to international trends.

The main contributions of this study are the following: i. To analysis the trends and dynamic of material and energy flows in a city of emerging economy through novelty indicators in different periods; ii. To evaluate the relationship the results of Bogotá in comparison with other Latin American countries to determine sustainable performance; iii. To contribute with analysis of flows and effects on environment from different approaches taking into account that studies related to energy and material flows are limited in emerging economies.

This paper is structured in the following sections: following the present introduction, the second section describes the main characteristics of Bogotá, section three presents the data and variables used in this study, the fourth section presents the results and their analysis. Finally, conclusions and future direction are presented in Sect. 5, while Appendix A shows the main environmental policies implemented in Bogotá.

\section{Case Study}

Bogotá is the capital of Colombia. The geological characteristics of Bogotá correspond to the high plateau. Bogotá has a diversity of high productivity soils, and its subsoil is rich in groundwater that, in many cases, is used by industry or services. Pressure on the environment is directly due to the increase of the population, that grew of 27,9\% in the last years (from a population of 6302000 in 2001 to a population of 8064000 in 2017), while the indicators show how Bogotá is fundamental for the economic, environmental and social development of the country, as it is the urban area with the highest population and density. Bogotá contributes to the economy through production, concentrating the most specialized productive sectors and contribution to value aggregate, which is reflected in exports, but it is also the city with the highest collection of imports 
and, in recent years, has managed to improve its social performance by reducing poverty and inequality. These indicators show and emphasize the importance of carrying out analyses of the sustainability of the city, especially for its importance and contribution to the country. Table 1 shows the important role that Bogotá plays for the Colombian economy: the city concentrates about the $16 \%$ of population and contributes to the $26 \%$ to the national GDP, and more importantly shares the $44 \%$ of national value added while importing the $48 \%$ of goods of the entire nation. The poverty index comparison also defines Bogotá as the main engine of the Colombian economy

Table 1

Main indicators for Bogotá and Colombia in 2017

\begin{tabular}{|llll|}
\hline Indicator & Colombia & Bogotá & \% Participation of Bogotá \\
\hline Population & 49291609 & 8064000 & $16.36 \%$ \\
\hline Economically active population & 24787801 & 4609000 & $18.59 \%$ \\
\hline Gross domestic product (billions of pesos at current prices) & 928067 & 244909 & $26.39 \%$ \\
\hline GDP per capita (current prices) & 18828100 & 30307765 & - \\
\hline Average per capita income of the unit of expenditure (current pesos) & 646298 & 1034681 & - \\
\hline 12 months variation of the Consumer Price Index (\%) & 4.6 & 4.1 & - \\
\hline Gross production (millions of Colombian pesos) year 2016 & 243468806 & 39023247 & $16.03 \%$ \\
\hline Value added (millions of Colombian pesos) year 2016 & 88355482 & 15465953 & $44.17 \%$ \\
\hline Export value Millions of dollars. FOB values. & 37769.6 & 2472.3 & $6.5 \%$ \\
\hline Import value Millions of dollars. CIF values. & 46075.7 & 22166 & 48.1 \\
\hline GINI coefficient & 0.508 & 0.498 & - \\
\hline Poverty index & $26.9 \%$ & $12.4 \%$ & - \\
\hline Source: The Bogotá District Economic Development Secretariat, 2018 & & & \\
\hline
\end{tabular}

\section{Methods And Data Description}

This study evaluates material and energy flows in household of Bogotá over time using secondary information reported for different local statistics institutions. The selection of data was determined from availability, consistency and integrity to provide and guarantee reliable estimations of flow changes in the period selected.

Data include both input and output flows, also considering the relationship between inputs (such as food, water, construction and other materials, raw materials, energy, capital, information, and people) and outputs (such as industrial products, goods, services, knowledge, waste, and emissions). Inputs are important because they support and allow societal activities, urban functions within a city, formation of urban stocks as infrastructure, housing, building, public space and green areas and parks and production of products and services and the whole urban management. Outputs determine the magnitude, distribution and internal interactions and feedbacks regulated by governance, policy, culture and individual and collective behaviour of the city as an urban system.

Temporal variation of the flows has been collected for the years of 2001, 2005, 2010, 2015 and 2017. The variables and indicators used in this study are selected from the available information of household that the city has and are used to search for a relationship between inputs and outputs over time. In addition, in order to carry out a study taking into account the growth of the city, the intensities or measurements per capita are calculated from the population data for each of the inputs and outputs analysed and normalize variables.

Inputs and outputs include the following data, which are compared and analysed trends in different period times taking into account the relationship between flows absolute and normalized by inhabitant and household sector:

Inputs:

\section{Water}

Consumption in the household sector ( $\mathrm{m}^{3} /$ year) and consumption per inhabitant per year ( $\mathrm{m}^{3} /$ inhab/year). The source is the water consumption database of the secretary of planning, District of Bogotá.

\section{Energy}


Consumption (electricity and natural gas) in the household sector (TJ/year) and consumption per inhabitant per year ( $\mathrm{m}^{3} /$ inhab/year). The source is the database of energy of UPME and the Superintendency of Public Services.

\section{Grey cement}

Consumption per year in the household sector (Ton/year) and consumption per inhabitant per year (Ton/ inhab/year). The source is the database of cement of the secretary of planning, District of Bogotá.

Outputs:

\section{Wastewater}

Generation of domestic discharges ( $\mathrm{m}^{3} /$ year) and generation of domestic discharges per inhabitant per year ( $\mathrm{m}^{3} /$ inhab/year). The source is the water consumption database of the secretary of planning, District of Bogotá.

\section{Emissions}

COx (Ton/year), SOx, NOx and particulate matter PM10 ( $\mu \mathrm{g} / \mathrm{m} 3)$ and COx (Ton/inhab/year). The source is the database of emissions of the environmental observatory of Bogotá, data is general and correspond to mobile sources.

\section{Solid waste}

Generation of domestic solid waste (Ton/year) and domestic solid waste per inhabitant per year ( $\mathrm{m}^{3} /$ inhab/year). The source is the solid waste database of the secretary of planning, District of Bogotá.

\section{Construction waste}

Generation for construction of household (Ton/year) and generation per inhabitant per year (Ton/inhab/year). The source is the solid waste database of the secretary of planning, District of Bogotá.

Together with these flows data on policies on water saving, energy, and mobility have been collected in order to better understand the temporal variation of the flows, focussing on 10 years and 15 years growth in Bogotá, to determine how policies have helped to improve performance of the city.

Moreover, temporal variation of data has been compared with other Latin American Large urban agglomerations, data used for the present study come from previous urban metabolism studies (see Kennedy, 2015; Facchini, 2017; Facchini, 2017a for full details), where urban metabolism (Bai, 2016, Kennedy, 2007) data have been collected according to a specific multi-layered survey developed for large urban agglomeration (Kennedy, 2014) to calculate.

\section{Results}

In this section, the trends and analysis of the flow of materials in different periods of time in the city of Bogotá are presented, taking into account the main inputs and outputs at a general level and as components where the dynamics of growth and reduction are observed according to different pressures or actions on the environment or the greater awareness of the inhabitants of the city. Following this analysis, the 10-year growth of Bogotá is compared with other large urban agglomerations, pointing out differences and analogies.

\subsection{Temporal variation of the flows in the period 2001-2017}

During the study period, the flows of materials and energy in the city of Bogotá have been increasing, especially due to population growth from 6302880 in 2001 to 8064000 in 2017 . This represents an annual increase of approximately 100000 inhabitants.

Figure 1 shows a comparison of the flow balance of materials and energy per capita for the period 2001-2017, and depicts the increase in certain flows, especially energy, cement, $\mathrm{CO}_{2}$ emissions and construction waste, reflecting the growth of the city. On the other hand, from the design and application of public policy instruments at the urban level, e.g. dissemination and awareness campaigns [BIB], the reduction of flows such as water and wastewater generation, were achieved, while the production of solid waste remained relatively stable. With regards to the in/out equilibrium of flows, figure 1 also shows that input and output flows of energy and water are in equilibrium, indicating that the distribution and collection infrastructures are managed in an efficient way.

A more detailed view is offered by Fig. 2, where the 10 years and 15 years growth rates are compared. It is interesting to notice that flows are divided in three categories: 
1. Significant increase (more than 50\%): GDP, Debris and cement, both in the 10 year and 15 year view.

2. Stability (between 0 and $50 \%$ ): Natural gas, total energy, $\mathrm{CO} 2$ emissions, solid waste, and electricity consumption.

3. Reduction (less than 0\%): Water consumption, wastewater, Particle PMx.

Considering the first category, it is interesting to point out that GDP experienced a significative increase in 15 years (230\%) and 10 years ( $92 \%$ ) while in the same period both population and the use of resources and output experience a different increase, while water (-5,2\% in 15 years), wastewater (-17,8\% in 15 years) and PMx emissions (- $9,2 \%$ in 10 years and - 37\% in 15 years) have been significantly reduced. The only flows that are both over $50 \%$ in both 10 and 15 years are those relative to the construction sector, with debris and cement. In particular, debris experienced the most significative growth in 15 years, reaching an increase of $150 \%$.

Considering the population as the main driver for urban expansion and urban flows, we show in Fig. 3 the elasticity of the metabolic flows with respect to population. As expected, both 10yrs and 15yrs GDP values are well above 1, 5 and 8, respectively. Such values are in line with other large urban agglomerations observed worldwide (Kennedy et al, 2015), while debris and cement elasticity reflect the important increase observed in Fig. 2. With regards to the other flows, is interesting to notice that natural gas, total energy, $\mathrm{CO} 2$ emissions and solid waste show elasticity values between 1 and 1,4, while electricity, water consumption (15yrs) wastewater (15yrs) and particle PMX show negative values or values lower than 1.

These results indicate the importance of understanding the specific issues related to a sustainable urban transition at the local level that implies a link between urban activities and urban planning. Musango et al. (2017) and U4SSC (2017) recommend the design and application of methods to calculate energy and material flows, ensuring a comparison for all cities, in both developed and developing countries, to analyse spatial and temporal issues in urban flows, to assess different effects of society such as a transdisciplinary study, to use a dynamic model, which allows evaluating physical and social processes as key elements in urban planning and design interventions, improving eco-efficiencies, integrating urban management and development plans, and promoting social inclusiveness, among other suggestions.

In the following subsections the paper discussed in deeper detail the temporal variation of the urban metabolism flows, highlighting the main actions implemented by the municipality to reduce the pressure of the city on the environment.

\subsection{Trends in water consumption and wastewater production}

In the urban sphere, water consumption is essential for different personal and business processes, and its use generates wastewater; thus, these types of consumption maintain a direct relationship for the study period. It is observed that in 2001, the total water consumption of the city was $61014567 \mathrm{~m}^{3}$, while in 2017 the consumption was $57811956 \mathrm{~m}^{3}$, indicating a decrease of $3202611 \mathrm{~m}^{3}$ during these years. A similar situation is observed with wastewater; in 2001, $65642718 \mathrm{~m}^{3}$ was produced, and in 2017 its production was $53988449 \mathrm{~m}^{3}$.

Figure 4 shows the trends in water flow and discharge per capita for Bogotá in different years of the study period, where there is a tendency to a more efficient use of this resource, which generates reduced discharge with consequent benefits for the environment.

These results are products of various public awareness campaigns to generate less waste and the adoption of saving technologies that have resulted in a rational and efficient use of water. These results concur with OECD $(2015,2018)$ and Torjada et al. (2019) in the context of Spain, where according to the specific context, it is fundamental to formulate and apply a combination of measures and action plans that integrate pricing and non-pricing measures and educational campaigns to achieve the more efficient management of water resources at the household and industrial levels. Moreover, it is important to constantly evaluate the results and impacts of implemented measures to guarantee applicability and effectiveness.

In addition to the implementation of a communication campaign oriented towards the voluntary saving of water, in critical situations of drought due to climatic variability or maintenance of treatment plants, user associations state that in recent years, the gradual dismantling of subsidies and the increase in the costs due to the greater consumption have limited the payment capacity of the low socio-economic strata 1, 2, 3 (CRA, 2016), which has influenced a lower consumption of water and, therefore, less dumping and emissions.

\subsection{Trends in energy consumption and emissions generation}

Energy consumption is vital for cities and is synonymous with development and progress. In the case of Bogotá, the two most important sources of energy for residential use are electricity and natural gas. The consumption of these two resources was 7240701.31 TJ in 2001 and 9646171.83 TJ in 2017, which is an increase of $33 \%$.

Figure 5 shows the per capita energy consumption for Bogotá as a total of electricity and natural gas. From 2001 to 2017 , there was an increase in consumption, while in recent years it has been reducing the same per inhabitant.

In the case of electricity, per capita consumption has remained almost constant, especially in recent years with a downward trend. In the case of natural gas, increases in consumption are evident until 2010, and then a reduction in consumption is observed, generating lower per capita consumption for this fuel and with slight increases in recent years. These results may be due to a new migration of users to electricity, mainly due to natural gas rationing or accidents that occurred with them. 
In general terms, it could be said that energy consumption in the residential sector of Bogotá has remained relatively stable with minor increases in electricity consumption, reductions in natural gas consumption and a slight increase in the last three years. These results may also be due to technological changes and increased awareness of the rational use of energy.

Policy makers and decision makers should evaluate electricity demand to determine the main drivers of efficient construction design, sociodemographic and physical dwelling characteristics, network planning and strategic instruments, regulations, socio-technical structures, and energy efficiency technologies and to capture the diversity of infrastructure characteristics, which could generate potential energy reduction and cost savings (Roberts et al., 2019, Satre-Meloy, 2019).

As a result of energy consumption, emissions that generate air pollution increased. Table 3 shows the pollutant loads in the air for the different periods. It is observed that $\mathrm{CO}_{2}$ emissions have increased slightly on average in recent years, sulfur dioxide and average nitrogen have shown a similar trend of maintaining or decreasing, and PM10 particulates have tended to decrease due mainly to improvements in the quality of the city fuels. However, in Bogotá, the need to improve the quality of fuels, especially in transport, is already observed due to the alerts for air quality that have occurred in 2019, indicating the importance of analysing the trends in emissions, taking the cycle of value of the energy sources used by sector and determine alternatives to improve air quality in the city of Bogotá.

Table 3

Air pollutant emissions in Bogotá 2001-2017

\begin{tabular}{|llllll|}
\hline Air pollutant emissions & 2001 & 2005 & 2010 & 2015 & 2017 \\
\hline $\mathrm{CO}_{2}$ emissions per capita Ton/inhab & 64.45 & 65.51 & 68.33 & 61.21 & 67.11 \\
\hline Annual average sulfur dioxide $\mu \mathrm{g} / \mathrm{m3}$ & $\mathrm{ND}$ & 0.013 & 0.020 & 0.019 & 0.013 \\
\hline Annual average nitrogen dioxide $\mu \mathrm{g} / \mathrm{m3}$ & $\mathrm{ND}$ & 0.026 & 0.038 & 0.035 & 0.024 \\
\hline Particulate matter PM10 $\mu \mathrm{g} / \mathrm{m}^{3}$ & 65 & 74 & 59 & 44 & 41 \\
\hline Note: NA not available & & & & & \\
\hline
\end{tabular}

Source: http://oab.ambientebogota.gov.co/es/listado-indicadores-por-recurso-natural

These results are consistent with the statement that improving urban air quality is one of the most demanding tasks facing policy makers worldwide, where it is important to determine the costs and benefits of measures that could include reductions in inefficient fossil fuel combustion and improvements in energy efficiency, which should reduce air pollutant emissions (Hewitt et al., 2019, WHO, 2017).

\subsection{Trends in cement consumption and generation of construction waste}

In the urbanization process, a large amount of construction material is required, which in parallel, generate construction waste that in many cases, due to their mixture, is difficult to recover and/or deal with the consequent problems of landfill occupation and pollution. In 2001, the consumption of grey cement in the city was 962,000 tons, and in $2017,1461,000$ tons were consumed, which was an increase of $52 \%$. Regarding the generation of debris, in the year 2001, 6132000 tons, and in 2017, 15487802 tons, were generated, which was an increase of three times compared to the base year. Figure 6 describes the trends in cement consumption and construction waste generation per capita in the city of Bogotá for the study period.

Cement consumption per inhabitant has remained relatively constant, while the generation of construction waste per person in the city has increased, mainly due to the dynamics of new construction and the modification of those existing in urban densification and expansion processes. Additionally, in recent years, in the city, the demand for materials for periodic housing remodelling, industrial and commercial areas have increased, which may suggest an increase in this consumption pattern and a greater added value to the construction.

Moreover, construction waste can be recycled or reused as building materials through integrated waste management systems that include waste sorting, reducing illegal dumping behaviour, promoting the government's financial subsidy on waste recycling, and increasing waste landfilling charges, which is an opportunity for extracting economic and environmental benefits from waste as reductions in $\mathrm{CO}_{2}$ emissions, energy use, natural resources and illegal landfills (Islam, 2019, Hao et al., 2019).

\subsection{Trends in the production of solid waste}

Another fundamental element to ensure sustainability in urban areas is the management of solid waste. In Bogotá, in the year 2001,1794430 tons of solid waste was generated, while in 2017 the generation was 2295821 tons, which is an increase of $28 \%$. Figure 7 shows the per capita generation of waste in Bogotá for the study period indicating that between 2001-2010 there was an increase in per capita waste generation and that in the last year, a downward trend has been achieved that could be attributed to greater awareness of the importance of reducing waste generation and contributing to recycling.

Page $7 / 15$ 
According to the World Bank (2019), managing waste is essential for achieving sustainable and liveable cities, especially in cities of developing countries. However, effective waste management is expensive (on average $20 \%-50 \%$ of municipal budgets) and complex. The main objectives of solid waste management include (Das et al., 2019) description of new technologies, strategic innovations and monitoring tools, definition of waste management scenarios, identification of the role of life cycle assessment and other modelling and simulation tools and alternatives for sustainable recycling and use of solid waste to achieve an integrated system characterized by efficiency, sustainable and socially supported.

These results show the importance of knowing the dynamics of the different inflows of inputs and outputs in urban areas in order to determine how actions can be achieved when the population takes responsibility for their environmental impacts. These results also illustrate how the population can be aware of the pollution and environmental problems and how local actions take precedence to impact global indicators, improve the environment and contribute to the sustainability of the city; these actions take into account that urban activities and processes are managed at a sub-national level by municipal or city governments, that should formulate effective action and processes to simultaneously improve and strengthen resource efficiency and productivity and achieve sustainable development (Musango et al., 2017).

\section{Comparison With Latin American Large Urban Agglomeration}

The 10 years variation of energy and material flows of Bogotá are compared with other large urban agglomeration of Latin America: Mexico City, Sao Paulo, Rio de Janeiro, Buenos Aires, and Lima. Tables 4 and 5 report the percentual growth and the flows elasticity with respect to population. Indeed, population is selected as guiding principle for the comparison of the metabolic flows.

Bogotá experienced the higher population growth rate, 18,5\% (in line with Lima) and against values around 10\% of Buenos Aires, Rio and Sao Paulo. between 3\% (Mexico City) and 18\% (Lima and Bogotá). Excluding Mexico City, the population growth of the other major cities in the region is between 10 and $20 \%$. Despite this relative homogeneity, the observed metabolic flows show consistent differences. Focusing on the energy sector, electricity consumption in Bogotá is located in the lower bracket of the interval, while Lima and Rio the Janeiro showed a significant increase. These figures are reflected in the elasticity value, that for Bogotá is 0.5 , the only one below one observed in the table. This is particularly relevant under the point of view of sustainability and resource conservation. Low elasticity values for resources mean that the city has been able to develop and increase its quality of life while reducing the pressure on environment. These findings are also valid for the total energy consumption. Table 4 shows values in the interval 18-55\%, showing Bogotá in the lower part of the interval.

Under the economic point of view GDP shows a consistent variability among the observed cities. GDP of Bogotá grew in line with Lima and Rio de Janeiro, while the elasticity values are significantly different: Bogotá shows 5 , while the other cities (excluding Lima) show higher values between 9 and 21, indicating that the population growth in Bogotá triggered in a reduced way the economic growth of the city.

Table 4

10 year (2001-2011) growth of selected Latin American Cities

\begin{tabular}{|llllll|}
\hline & GDP & Population & Electricity & Total Energy & Water \\
\hline Mexico City & 65,8 & 3,0 & 3,6 & 32,6 & NA \\
\hline Sao Paulo & 179,5 & 10,9 & 49,0 & 42,2 & 23,9 \\
\hline Rio de Janeiro & 98,0 & 9,6 & 103,6 & 51,5 & 41,5 \\
\hline Buenos Aires & 109,3 & 11,7 & 39,2 & 18,2 & NA \\
\hline Lima & 91,99 & 17,64 & 135,14 & 55,11 & 32,83 \\
\hline Bogota & 92,1 & 18,5 & 8,4 & 25,6 & 14,6 \\
\hline
\end{tabular}

Table 5

10 year (2001-2011) population elasticity of selected Latin American Cities

\begin{tabular}{|lllll|}
\hline & GDP & Electricity & Total Energy & Water \\
\hline Mexico City & 21,8 & 1,2 & 10,8 & NA \\
\hline Sao Paulo & 16,5 & 4,5 & 3,9 & 2,2 \\
\hline Rio de Janeiro & 10,2 & 10,8 & 5,4 & 4,3 \\
\hline Buenos Aires & 9,3 & 3,3 & 1,6 & NA \\
\hline Lima & 5,2 & 7,7 & 3,1 & 1,9 \\
\hline Bogota & 5,0 & 0,5 & 1,4 & 0,8 \\
\hline
\end{tabular}

Page $8 / 15$ 


\section{Conclusions And Future Directions}

This paper reports the analysis of the urban metabolism of Bogotá for the period 2001-2017, showing the fundamental elements for understanding where the main environmental problems are generated and how actions could be taken.

The results show that at a global level, most of the flows increased under pressure from population growth and city densification/expansion. However, when reviewing the flows at the inhabitant level, greater efficiency is observed, which demonstrates that day-by-day, citizens are more aware of consumption and the environmental problems that they can generate. During the study period, the flows that increased in the city were the consumption of energy and cement and the generation of $\mathrm{CO}_{2}$ and debris emissions, which is consistent with the dynamics of the city. In contrast, the reduction in water consumption and the generation of landfills and the production of solid waste were relatively stable. These findings are also confirmed by the 10 year and 15 year growth analysis, showing that the elasticity of the metabolic flows in relation to the population increase are either reduced or in the lower bracket when compared with other large urban agglomerations in the Latin America Region.

Furthermore, the comparison of the 10 year growth of Bogotá highlighted significant differences, especially regarding the use of metabolic flows

This study demonstrates that urban systems present different opportunities for the development and application of strategies, plans and programmes for the efficient management of resources within the framework of integral urban planning. In addition, the paper seeks to migrate from a linear behaviour of flow of materials to more circular processes, making the provision of various urban and public products and services to the inhabitants and economic activities sustainable. In this way, it is possible to promote change in citizen rationalizations and consumption patterns oriented towards the best use of resources, reducing the generation of waste to strengthen the various aspects of the urban system.

From the analysis presented here clearly emerged the prioritized role of public policy instruments that allow, at the macrolevel, impacting citizen actions in favour of sustainability and generating an adequate urban environmental management based on a baseline that allows the measurement of the impact of the different programmes that promote the care of the environment.

Future work will be devoted to a better understanding of the metabolic flows in a circular economy perspective, also making use of a novel urban model that integrates urban metabolism and Life-cycle assessment (Maranghi, 2020).

\section{Declarations}

\section{Acknowledgement}

This paper is the result of project entitled "Modelado y Simulación del Metabolismo Urbano de Bogotá D.C.", code: 111974558276 financided by Colciencias [Contract Colciencias 022-2017] and this paper took inputs of project entitled "Energy and material flows in Bogota: relationships with quality of life, utilities, and comparison with other Latin American cities" code: 002-2016 financed by Fondazione Centro Studi Enel (Enel Foundation).

\section{Appendix A: Policies And Regulation Implemented To Reduce Environmental Impact}

Table 6 shows different policies and regulations developed in Colombia and specially in Bogotá with the aim to foster the rational and efficient use of natural resources and solid waste management. The policies here collected allowed for a greater awareness of population in in caring for and protecting natural resources, efficiency use and rational generation of solid waste. 
Table 6

Main policies and regulations in Bogotá to improve environmental impacts

\begin{tabular}{|c|c|}
\hline Resources & Policies and regulations \\
\hline \multirow[t]{8}{*}{ Water } & $\begin{array}{l}\text { Regulations are based on integral management with participatory approach that involving users, planners and decision } \\
\text { makers at all levels. }\end{array}$ \\
\hline & $\begin{array}{l}\text { Programs have been defined from the characterization of the demand for water (qualify and quantify) by different users and } \\
\text { the analysis of profile consumption to undertake actions aimed at changes that optimize its use, as well as the promotion of } \\
\text { practices that favour the sustainability of ecosystems and the reduction of contamination. }\end{array}$ \\
\hline & $\begin{array}{l}\text { Law 373/1997: The program on conservation and efficient use of water (a set of projects and actions for efficient use of } \\
\text { water). }\end{array}$ \\
\hline & $\begin{array}{l}\text { National policy for Integral Management of Water Resource / 2010: with a special principle (6): "fresh water is considered a } \\
\text { scarce resource and, therefore, its use will be rational and will be based on saving and efficient use" }\end{array}$ \\
\hline & $\begin{array}{l}\text { Decree 3570/2011: Integral management of water resources, in order to promote the conservation and sustainable use of } \\
\text { water. }\end{array}$ \\
\hline & Decree 485/2011: The Bogotá District Plan of Water. \\
\hline & Signing of agreements with productive sectors of interest to promote efficient use of water. \\
\hline & $\begin{array}{l}\text { Tariffs differentiated by the water consumption guarantee the minimum subsistence and average consumption. A higher } \\
\text { consumption, higher cost by cubic meter. }\end{array}$ \\
\hline \multirow[t]{7}{*}{ Energy } & $\begin{array}{l}\text { Policies and regulations on energy efficiency seek to ensure energy supply, based on the adoption of new technologies and } \\
\text { good consumption habits, in order to optimize the management and use of available energy resources. Energy efficiency is a } \\
\text { driver to increase national productivity and competitiveness, and is one of the main strategies for mitigating environmental } \\
\text { impacts in the energy chain. }\end{array}$ \\
\hline & Law 697/2001: The Programme for Rational and Efficient Energy Use and other Forms of Non-Conventional Energy (PROURE) \\
\hline & $\begin{array}{l}\text { Resolutions } 180919 / 2010 \text { and } 41430 / 2015 \text { : The indicative action plans to develop and apply energy efficiency goals and } \\
\text { actions by priority consumption sector. }\end{array}$ \\
\hline & Priority programs: i. Residential: Illumination, refrigeration, and building. \\
\hline & ii. Industrial sector: Boilers, illumination, driving force, cogeneration, combustion, energy management, ecolabel, cool chain. \\
\hline & Transport: Technology reconversion, good practices, transport means. \\
\hline & Services sector (government, services): illumination, refrigeration, public lighting, building, air conditioning. \\
\hline Solid Waste & $\begin{array}{l}\text { Integral solid waste management has developed different programs and actions as the formulation of guidelines for waste } \\
\text { management in different industrial sectors, subsystem of information to follow and measure of waste generation, recycling } \\
\text { process, tariffs and other strategies to decrease waste management generation and increase recycling and potential use of } \\
\text { these materials. }\end{array}$ \\
\hline \multirow[t]{3}{*}{$\begin{array}{l}\text { Construction } \\
\text { Waste }\end{array}$} & $\begin{array}{l}\text { Resolution 2397/2011: the entities, generators, transporters, exploiters and sites for the temporary and final disposal of } \\
\text { construction waste go in the same line and that this allows appropriate management to be carried out in the city, resulting in a } \\
\text { lower environmental impact. }\end{array}$ \\
\hline & $\begin{array}{l}\text { Resolution 00715/2013: Technical-environmental guidelines for the activities of use and treatment of construction and } \\
\text { demolition waste }\end{array}$ \\
\hline & Decree 586/2015: The efficient and sustainable model of construction and demolition waste management is adopted \\
\hline
\end{tabular}

\section{References}

1. Bai, X. (2016). Eight energy and material flow characteristics of urban ecosystems. Ambio 45(7): 819-830.

2. Barles, S. (2010). Society, energy and materials: the contribution of urban metabolism studies to sustainable urban development issues. Journal of Environmental Planning and Management 53, 439-455.

3. CRA, (2016). Statistical bulletin 2006-2018. https://www.cra.gov.co/seccion/inicio.html

4. Czamanski, D., Broitman, D. (2018). The life cycle of cities. Habitat International 72, 100-108.

5. Dai, T, Liu, R. (2018). Dematerialization in Beijing from the perspective of material metabolism. Journal of Cleaner Production $201,792-801$.

6. Das, S., Lee, S., Kumar, P., Kim, K., Lee, S., Bhattacharya, S. (2019). Solid waste management: Scope and the challenge of sustainability. Journal of Cleaner Production 228, 658-678.

7. EEA (2015). Urban sustainability issues - What is a resource-efficient city?. EEA Technical report No 23/2015. https://www.eea.europa.eu/publications/resource-efficient-cities/file 
8. Facchini, A, Cardenas U., Kahat, R., Vazquez-Rowe I., Garcia-Torres S., Mele R., Caldarelli, G., Kennedy C. (2017a) The urban metabolism of Lima: perspectives and policy indications for $\mathrm{GHG}$ emission reduction. $10^{\text {th }}$ BIWAES, Naples.

9. Facchini, A., Kennedy, C., Stewart, I., \& Mele, R. (2017). The energy metabolism of megacities. Applied Energy, 186, 86-95.

10. Maranghi, S., Parisi, M. L., Facchini, A., Rubino, A., Kordas, O., \& Basosi, R. (2020). Integrating urban metabolism and life cycle assessment to analyse urban sustainability. Ecological Indicators, 112(December 2019), 106074. https://doi.org/10.1016/j.ecolind.2020.106074

11. Ferrao, P., Fernández, J. (2013). Sustainable Urban Metabolism. MIT Press. Cambridge, Massachusetts, London, England.

12. Giampietro, M. (2019). On the Circular Bioeconomy and Decoupling: Implications for Sustainable Growth. Ecological Economics $162,143-156$.

13. Grimm, V., Wissel, C. (1997). Babel, or the ecological stability discussions: an inventory and analysis of terminology and a guide for avoiding confusion. Oecologia 109, 323-334.

14. Hao, J., Yuan, H., Liu, J., Chin, S., Lu, W. (2019). A model for assessing the economic performance of construction waste reduction. Journal of Cleaner Production 232, 427-440.

15. Hewitt, N., Ashworth, K., MacKenzie, R. (2019). Using green infrastructure to improve urban air quality (GI4AQ). Ambio https://doi.org/10.1007/s13280-019-01164-3

16. Islam, R., Nazifa, T., Yuniarto, A., Uddin, A., Salmiati, S., Shahid, A. (2019). An empirical study of construction and demolition waste generation and implication of recycling. Waste management 95, 10-21.

17. Kemp-Benedict, E. (2018). Dematerialization, Decoupling, and Productivity Change. Ecological Economics 150, $204-216$.

18. Kennedy, C., Cuddihy, J., \& Engel-Yan, J. (2007). The Changing Metabolism of Cities. Journal of Industrial Ecology.

19. Kennedy, C., Stewart, I. D., Ibrahim, N., Facchini, A., \& Mele, R. (2014). Developing a multi-layered indicator set for urban metabolism studies in megacities. Ecological Indicators, 47.

20. Kennedy, C., Stewart, I., Facchini, A., Cersosimo, I., Meleb, R., Chenc, B., Uda, M., Kansald, A., Chiu, A., Kim, K., Dubeuxg, C., Lebre, E., Cunha, B., Pincetl, S., Keirstead, J., Barles, S., Pusaka, S., Gunawan, S., Adegbile, M., Nazariha, M., Hoque, S., Marcotullio, P., González, F., Genena, T., Ibrahim, N., Farooqui, R., Cervantes, R., Duran, A (2015). Energy and material flows of megacities. PNAS 112, 5985-5990 www.pnas.org/cgi/doi/10.1073/pnas.1504315112

21. Lin, T., Gibson, V., Cui, S., Yu, C., Chen, S., Ye, Z., Zhu, Y. (2014). Managing urban nutrient biogeochemistry for sustainable urbanization. Environmental Pollution 192, 244-250.

22. Moore, J., Kissinger, M., \& Rees, W. E. (2013). An urban metabolism and ecological footprint assessment of Metro Vancouver. Journal of Environmental Management, 124, 51-61.

23. Musango, J.K., Currie, P., Robinson, B. (2017) Urban metabolism for resource efficient cities: from theory to implementation. Paris: UN Environment.

24. OECD (2015). OECD principles on water governance. Paris: Organisation for Economic Co- operation and Development.

25. OECD (2018). Implementing the OECD principles on water Governance. Indicator framework and evolving practices. Paris: Organisation for Economic Co-operation and Development.

26. Pao, H., Chen, C. (2019). Decoupling strategies: CO2 emissions, energy resources, and economic growth in the Group of Twenty. Journal of Cleaner Production 206, 907-919.

27. Pataki, D., Carreiro, M., Cherrier, J., Grulke, N., Jennings, V., Pincetl, S., Pouyat, R., Whitlow, R., Zipperer, W. (2011). Coupling biogeochemical cycles in urban environments: ecosystem services, green solutions, and misconceptions. Front Ecol Environ 9, 27-36 doi:10.1890/090220

28. Patrício, J., Costa, I., Niza, S. (2015). Urban material cycle closing e assessment of industrial waste management in Lisbon region. Journal of Cleaner Production 106, 389-399.

29. Prendeville, S., Cherim, E., Bocken, N. (2018). Circular Cities: Mapping Six Cities in Transition. Environmental Innovation and Societal Transitions 26, 171-194.

30. Roberts, M., Haghdadi, M., Bruce, A., MacGill, I. (2019). Characterisation of Australian apartment electricity demand and its implications for low-carbon cities. Energy 180, 242-257.

31. Rosado, L., Kalmykova, Y., Patrício, J. (2017). Reprint of: Urban metabolism profiles. An empirical analysis of the material flow characteristics of three metropolitan areas in Sweden. Journal of Cleaner Production 163, S254-S266.

32. Satre-Meloy, A. (2019). Investigating structural and occupant drivers of annual residential electricity consumption using regularization in regression models. Energy 174, 148-168.

33. Silvestre, M., Favuzza, S., Sanseverino, E., Zizzo, G. (2018). How Decarbonization, Digitalization and Decentralization are changing key power infrastructures. Renewable and Sustainable Energy Reviews 93, 483-498.

34. Song, T., Yang, Z., Chahine, T. (2016). Efficiency evaluation of material and energy flows, a case study of Chinese cities. Journal of cleaner production 112, 3667-3675

35. Tozer, L. (2019). The urban material politics of decarbonization in Stockholm, London and San Francisco. Geoforum 102, 106-115. 
36. The Bogotá District Economic Development Secretariat, 2018. Anuario de Estadísticas Económicas y Fiscales de Bogotá 2017. http://observatorio.desarrolloeconomico.gov.co/ dinamica-economica-y-distribucion/anuario-de-estadisticas-economicas-y-fiscales-de-bo gota-2017

37. Tomić, T., Schneider, D. (2018). The role of energy from waste in circular economy and closing the loop concept - Energy analysis approach. Renewable and Sustainable Energy Reviews 98, 268-287.

38. Tortajada, C., González-Gómez, F., Biswas, A., Buurman, J. (2019). Water demand management strategies for water-scarce cities: The case of Spain. Sustainable Cities and Society 45, 649-656.

39. U4SSC (2017). Implementing Sustainable Development Goal 11 by connecting sustainability policies and urban- planning practices through ICTs. U4SSC series.

https://www.unece.org/fileadmin/DAM/hlm/documents/Publications/U4SSC_Brochure_Implementing_sustainable_development_goal_11.pdf

40. United Nations. (2015). Adoption of the Paris Agreement. Conference of the Parties on Its Twenty-First Session.

41. United Nations (2019). World urbanization prospects: The 2018 revision.

42. UNEP (2012). Global Initiative for Resource Efficient Cities. https://europa.eu/ capacity4dev/ file/13847/

43. WHO (2017). Public health policy for outdoor air quality.

https://www.who.int/phe/health_topics/outdoorair/databases/public_health_policy/en/

44. World Bank (2019). Solid Waste Management. https://www.worldbank.org/en/topic/urbandevelopment/brief/solid-waste-management

\section{Figures}
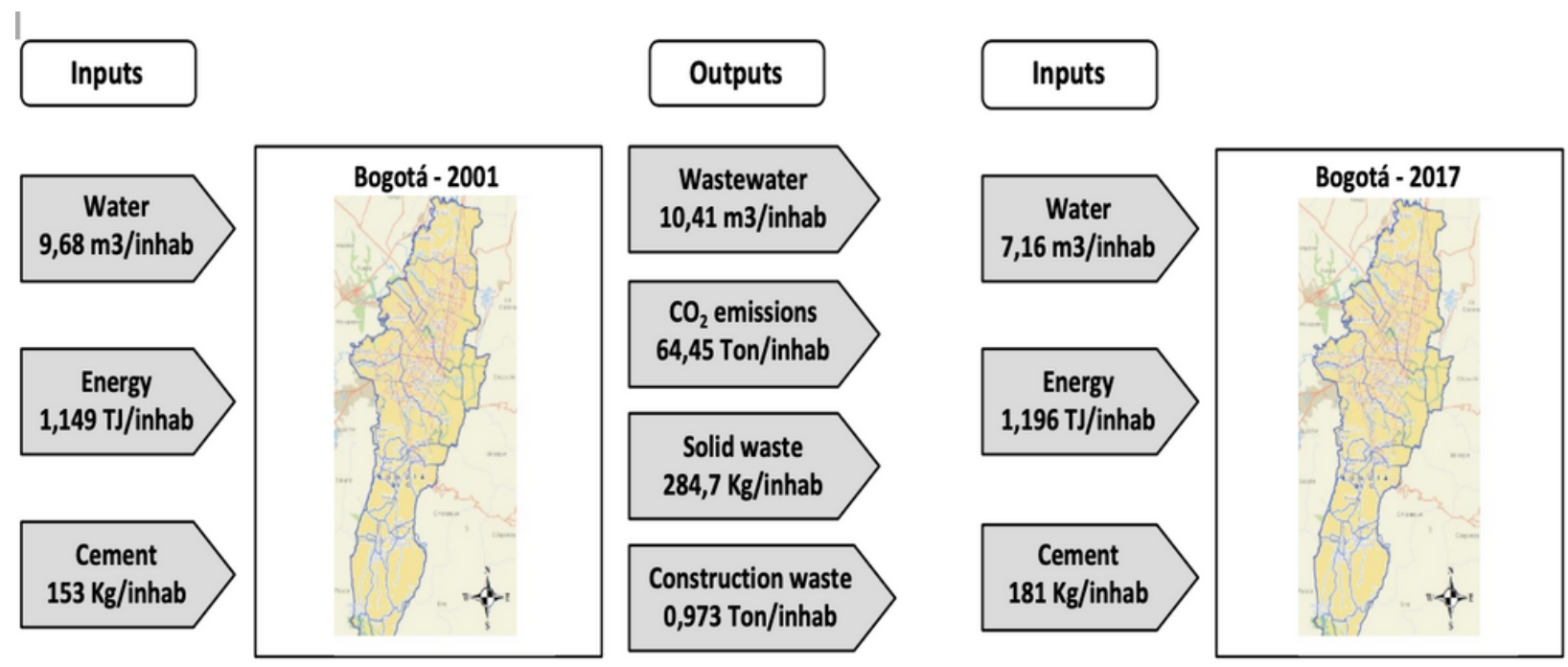

Outputs

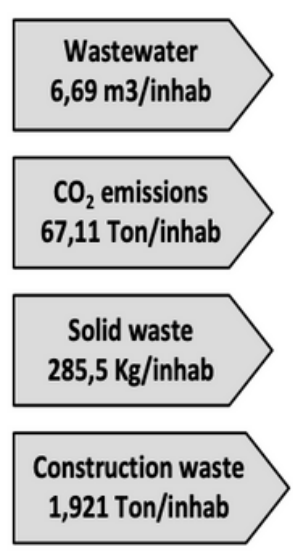

Figure 1

Comparative analysis of the flow of materials from Bogotá year 2001 and 2017 


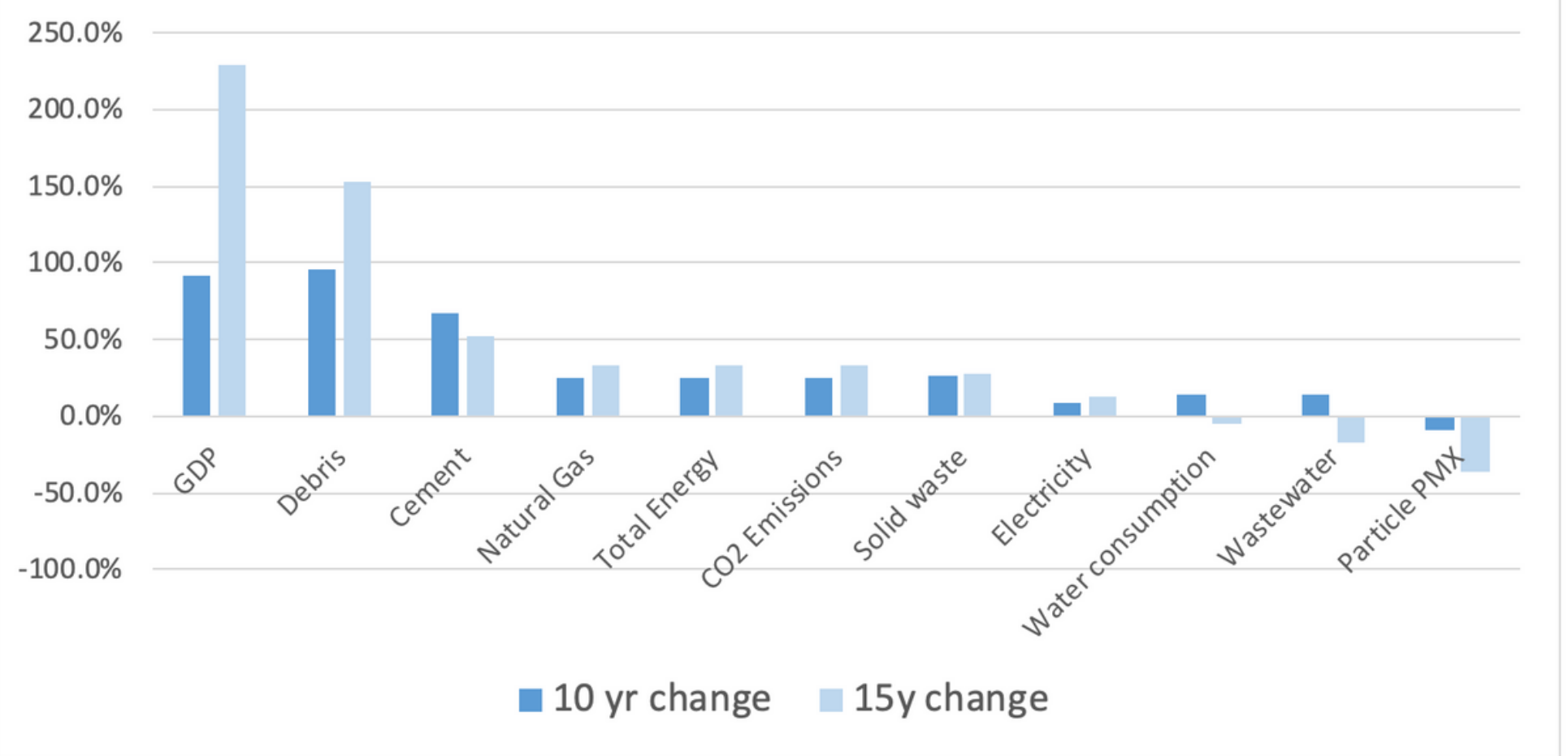

Figure 2

Comparison of 10 years and 15 years growth rates for the main input and outputs of Bogotá

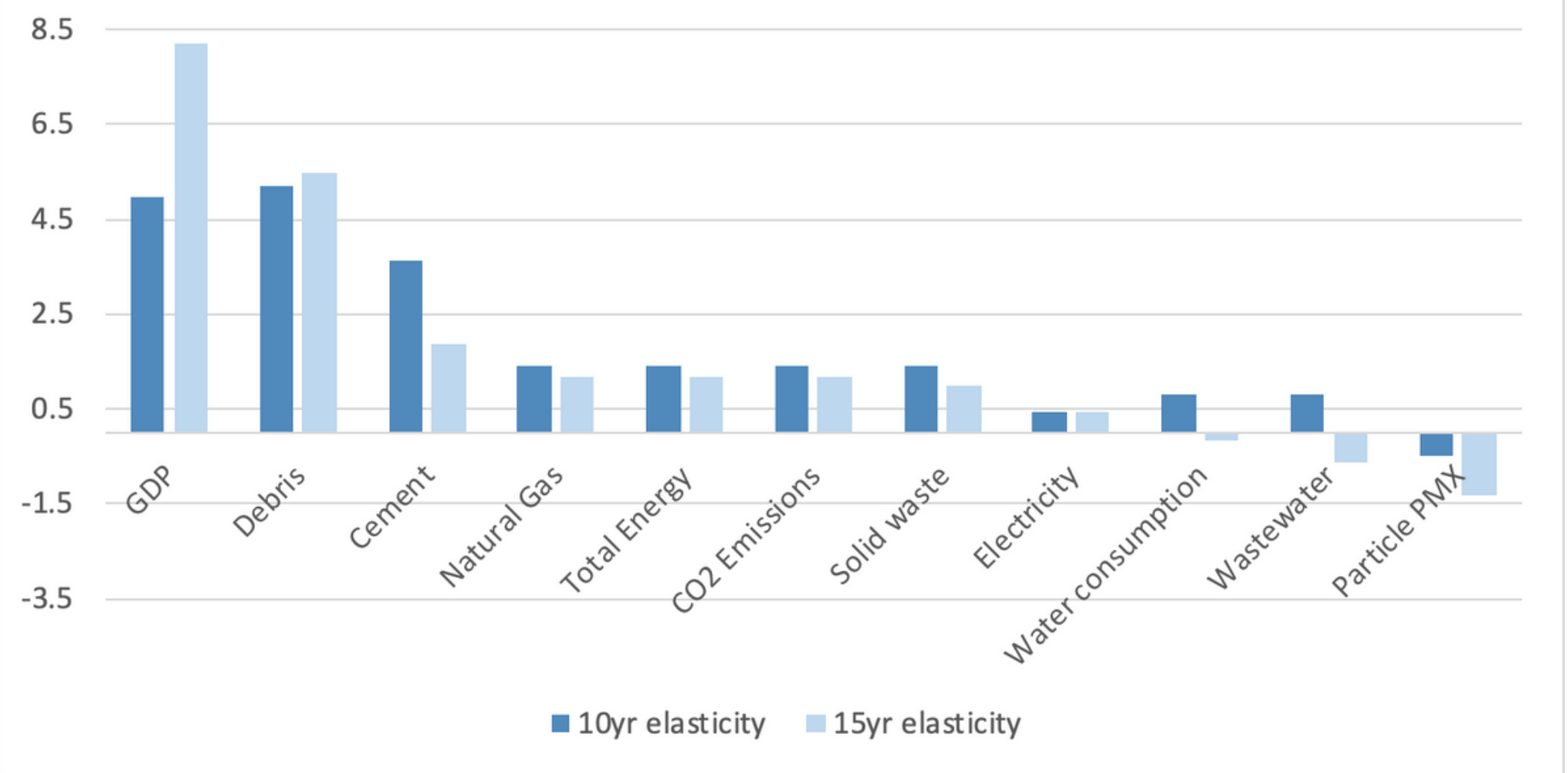

\section{Figure 3}

Comparison of 10 years and 15years elasticity of flows with respect to population 


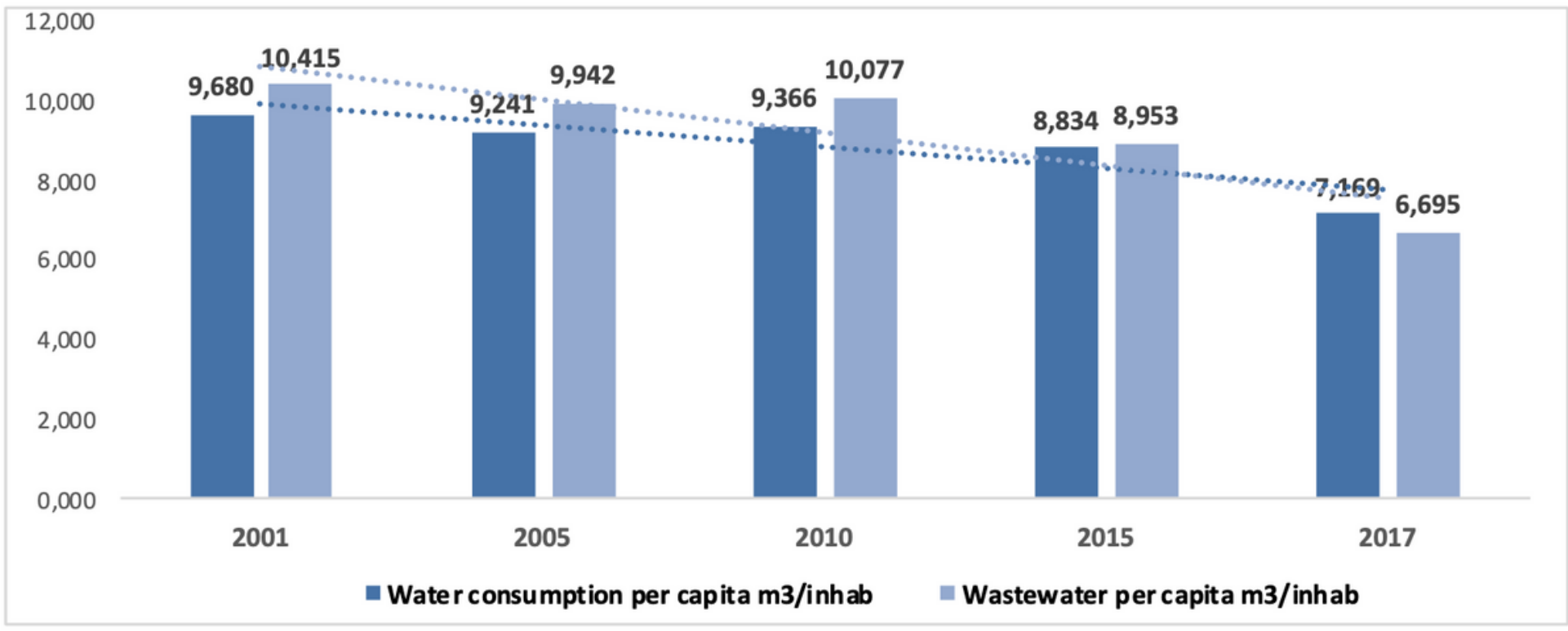

Figure 4

Trends in water consumption and generation of waste per capita in Bogotá 2001-2017

\begin{tabular}{|c|c|c|c|c|c|}
\hline \multicolumn{6}{|c|}{ Energy consumption $\mathrm{TJ} / \mathrm{hab}$} \\
\hline & & & 1,218 & & \\
\hline 1,200 & & & & & 1,196 \\
\hline 1,180 & & 1,168 & & & \\
\hline 1,160 & 1,149 & & & \multirow{7}{*}{1,091} & \\
\hline 1,140 & & & & & \\
\hline 1,120 & & & & & \\
\hline 1,100 & & & & & \\
\hline 1,080 & & & & & \\
\hline 1,060 & & & & & \\
\hline 1,040 & & & & & \\
\hline$x, 0<0$ & 2001 & 2005 & 2010 & 2015 & 2017 \\
\hline
\end{tabular}

\section{Figure 5}

Energy consumption per capita for Bogotá 2001-2017 


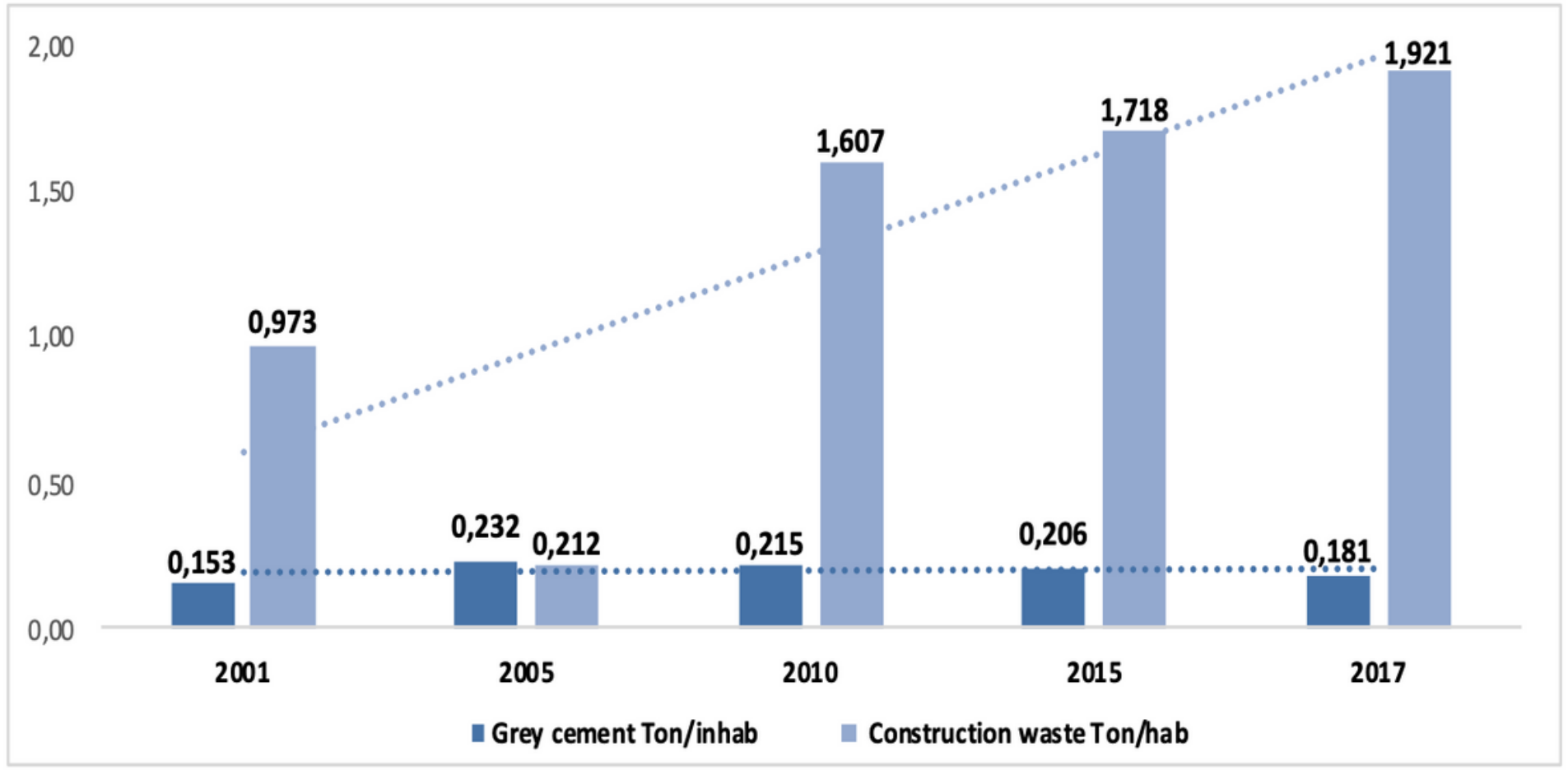

\section{Figure 6}

Trends in cement consumption and generation of waste construction per capita in Bogotá, 2001-2017

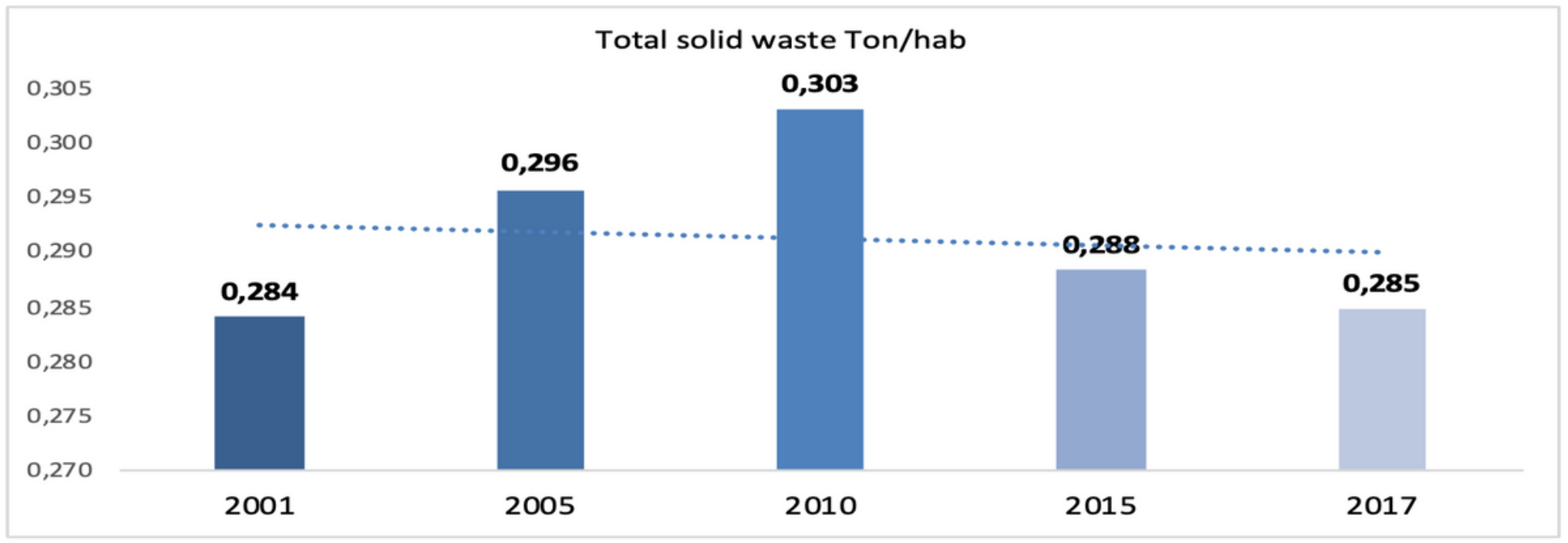

\section{Figure 7}

Production of solid waste per capita in the city of Bogotá, 2001-2017 